\title{
Inflammation is associated with future depressive symptoms among older adults
}

\author{
Erin Bondy ${ }^{\text {a, }, \text { Sara A. Norton }}{ }^{\text {a }}$, Michaela Voss ${ }^{\text {a }}$, Rebecca B. Marks ${ }^{\text {a }}$, Michael J. Boudreaux ${ }^{\text {a }}$, \\ Michael T. Treadway ${ }^{\mathrm{b}}$, Thomas F. Oltmanns ${ }^{\mathrm{a}}$, Ryan Bogdan ${ }^{\mathrm{a}, * *}$ \\ ${ }^{a}$ Department of Psychological and Brain Sciences, Washington University in St. Louis, USA \\ ${ }^{\mathrm{b}}$ Department of Psychology, Emory University, USA
}

\section{A B S T R A C T}

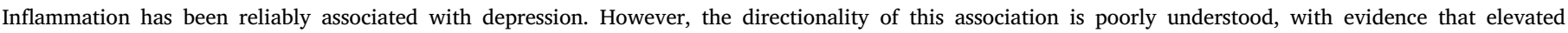

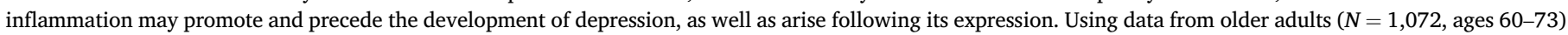

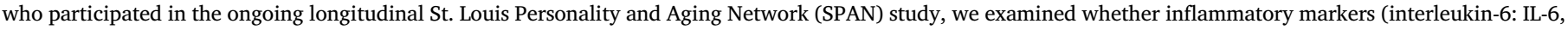

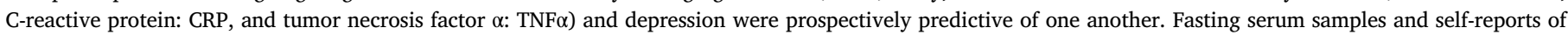

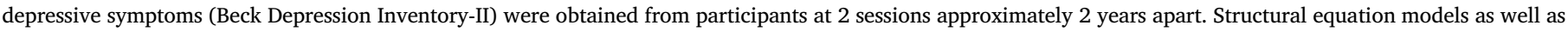

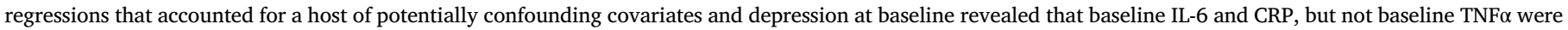

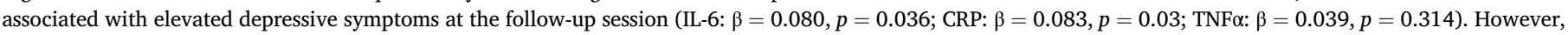

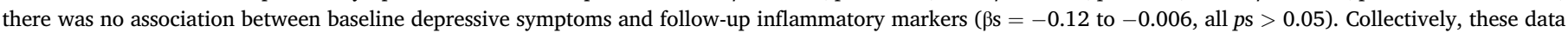

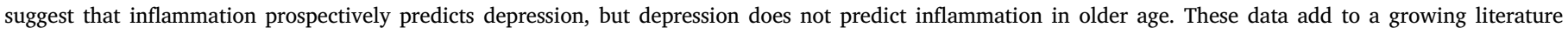
suggesting that inflammatory signaling may plausibly promote the development of depression.

\section{Introduction}

Depression is a growing public health concern that manifests as individual suffering and substantial socioeconomic costs (GBD 2017 Disease and Injury Incidence and Prevalence Collaborators, 2018). While depression is less common among older adults relative to younger adults, later life depression is associated with increased age-related disease (e.g., cardiovascular disease) and reductions in cognitive and social function (Fiske et al., 2009). Remarkably little is known about the etiology of late life depression, but emerging evidence suggests that systemic inflammation, which increases with age (Ferrucci and Fabbri, 2018), may play a pivotal role.

Converging evidence supports theory that inflammation may causally influence depression (e.g., Kiecolt-Glaser et al., 2015; Miller and Raison, 2016). First, depression has been robustly associated with elevated inflammatory markers, most notably interleukin-6 (IL-6), C-reactive protein (CRP), and tumor necrosis factor $\alpha$ (TNF $\alpha$; for meta-analyses see: Dowlati et al., 2010; Howren et al., 2009; Liu et al., 2017; Mac Giollabhui et al., 2020; Valkanova et al., 2013). Second, depression is common among individuals with physical health conditions characterized by elevated inflammation including cardiovascular disease and diabetes (Ridker, 2007). Third, transient increases in proinflammatory cytokines induce sickness behaviors that mirror depressive symptoms, such as anhedonia, sleep disturbance, and fatigue (Anisman et al., 2005; Dantzer et al., 2008; Sparkman et al., 2006). Fourth, inflammatory challenges in non-human animal models (e.g., rodents, non-human primates; Kaster et al., 2012, Dobos et al., 2012) and humans (Capuron et al., 2004; Moieni et al., 2015; Reichenberg et al., 2001) induce depressive-like symptomatology. Further, antidepressant medication and psychotherapy reduce inflammatory signaling (Hannestad et al., 2011; Leonard, 2014; Moreira et al., 2015), and anti-inflammatory medication has anti-depressant effects among depressed individuals (Köhler et al., 2014; Miller et al., 2009; Raison et al., 2013). Fifth, increases in central levels of pro-inflammatory cytokines have a number of effects on monoamine levels in a manner consistent with mechanisms thought to be involved in major depression (e.g., reducing serotonin and dopamine, increasing oxidative stress; Leonard, 2018; Treadway et al., 2019). Collectively, this

\footnotetext{
* Corresponding author. CB 1125, Psychological and Brain Sciences, Bldg Room 451B, Washington University in St. Louis, One Brookings Drive, St. Louis, MO, 63130, USA.

** Corresponding author. CB 1125, Psychological and Brain Sciences, Bldg Room 453, Washington University in St. Louis, One Brookings Drive, St. Louis, MO, 63130, USA.

E-mail addresses: ebondy@wustl.edu (E. Bondy), rbogdan@wustl.edu (R. Bogdan).
} 


\begin{tabular}{|ll|}
\hline Abbreviations: \\
IL-6 & interleukin-6 \\
TNF $\alpha$ & tumor necrosis factor $\alpha$ \\
CRP & C-reactive protein \\
BDI-II & Beck Depression Inventory II \\
\hline
\end{tabular}

evidence suggests that inflammation may plausibly be depressogenic.

The majority of studies investigating links between inflammation and depression have been cross-sectional, although there are accumulating longitudinal efforts. A recent meta-analysis of prospective associations between inflammation and depression found evidence for associations between inflammation and subsequent depression for both CRP (study $n$ $=18$, participant $n=38,469, \mathrm{f}(r)=0.058$ ) and IL-6 (study $n=11$, participant $n=9,953, \mathrm{f}(r)=0.053$ ), but not TNF $\alpha$ (study $n=5, \mathrm{f}(r)=$ -0.008; Mac Giollabhui et al., 2020). Further, baseline depression was associated with future CRP (study $n=14$, participant $n=32,078, \mathrm{f}(r)=$ 0.051 ) and IL-6 (study $n=6$, participant $n=2,949, \mathrm{f}(r)=0.09$ ), but not TNF $\alpha$ (study $n=5, \mathrm{f}(r)=0.015$ ). However, given animal and human research demonstrating associations between TNF $\alpha$ and depression (Kaster et al., 2012; Raison et al., 2013), further study is warranted. Moreover, a previous meta-analysis established a link between TNF $\alpha$ and major depression, noting however that significant variability across studies weakened presumed associations (Haapakoski et al., 2015). Indeed, the magnitude of associations across studies examining inflammatory markers and depression are often reduced when adjusted for relevant covariates (Mac Giollabhui et al., 2020), and variability in the use of covariates across studies may contribute to equivocal conclusions across studies (Smith et al., 2018).

Although inflammation and depression are associated across the lifespan, emerging evidence suggests that this may be more pronounced in later life. Aging is associated with elevated inflammation (Franceschi et al., 2017; Franceschi and Campisi, 2014) and the association between inflammation and depression is potentiated in late life (Grosse et al., 2015; Mac Giollabhui et al., 2020), contributing to speculation that inflammation may play a more prominent role in later-life depression (Alexopoulos and Morimoto, 2011).

\subsection{The current study}

Here, we tested whether inflammation (i.e., CRP, IL-6, and TNF $\alpha$ ) and depression are prospectively predictive of one another. To this end, we used data ( $n=327-791$ ) from the ongoing longitudinal St. Louis Personality and Aging Network (SPAN) study of older adults (ages 60-73). In light of existing literature, we hypothesized that higher IL-6, CRP, and TNF $\alpha$ would be associated with greater future depressive symptoms. As relationships between depression and future inflammation have been less reliably reported in the literature (Mac Giollabhui et al., 2020), particularly among older adults (Au et al., 2015; Gimeno et al., 2009), we hypothesized that depression may or may not predict future inflammation.

\section{Method}

\subsection{Participants and procedure}

The SPAN study is an ongoing longitudinal study assessing a wide range of personality, health, social, experiential, and biological characteristics among a representative baseline sample of 1,630 older adults residing in the St. Louis metropolitan area (ages 55-65 at baseline, $M=$ 59.5, $S D=2.7 ; 55 \%$ female; 65\% European American; 32\% African American; Oltmanns, Rodrigues, Weinstein and Gleason, 2014). Participants were recruited using listed phone numbers that were crossed with census data in order to identify households with at least one member in the eligible age range. When more than one person in a household was in the target age range, the conservative Kish method (Kish, 1949) was used, which enables the random selection of one individual from the household (i.e., sampling without replacement). If the target person refused to participate, other eligible residents in the household were not included (Oltmanns et al., 2014). Individuals were excluded if they lacked a permanent residence, were not fluent in English, could not read at a 6th-grade level, or had active psychotic symptoms.

Each participant completed a 3-h in-person assessment at baseline ( $N$ $=1,630$; baseline), and at 3 subsequent in-person follow-up (IPFU) sessions approximately 2 years apart (IPFU-1, $n=1,260$; IPFU-2, $n=1067$; IPFU-3, $n=906$, ongoing; Fig. 1). A fasting blood sample was collected from consenting participants typically within 2 weeks of IPFU-2 $(n=$ $791)$ and IPFU-3 $(n=578)$. Participants were also asked to complete a short sequence of mailed or online follow-up questionnaires that were administered approximately every 6 months after entering the study. Participants received $\$ 60$ for each in-person interview and $\$ 10$ for each set of questionnaires completed. Participants who consented to the optional blood draw at each time point were given $\$ 20$ additional in compensation. All protocols were approved by the Washington University in St. Louis Institutional Review Board. Data used in analyses of this study include participants who completed at least one blood draw sessions (i.e., IPFU-2 and/or IPFU-3). Compared to participants who completed IPFU-2 but not the corresponding fasting blood draw, no differences in depressive symptoms from those who had blood drawn were found $(t=-0.312, p>0.05)$. Similarly, participants who completed IPFU-3 but not the corresponding fasting blood draw did not differ from those did provide blood $(t=0.5, p>0.05)$. Analytic samples varied based on available inflammatory marker data (bivariate correlation Ns: 398-739; SEM analyses Ns: 379-463; regression with covariates Ns: 327-457). When comparing participants included in the SEM analysis of depression and IL- 6 to those not included, group differences in depressive symptoms and IL-6 levels at IPFU-2 emerged. Namely, those who were not included in analyses (due to lack of IPFU-3 data) had more depressive symptoms $(t=1.932, p<0.05)$ and higher levels of IPFU-2 IL$6(t=3.241, p<0.05)$ than those who completed the follow up. Similarly, individuals not included in the SEM analysis of depression and CRP had higher levels of CRP at IPFU-2 than those included ( $t=2.189, p<$ $0.05)$. No group differences emerged when comparing individuals included in the depression and TNF $\alpha$ analysis to those not included.

\subsection{Measures}

\subsubsection{Inflammatory markers}

Morning fasting blood samples were collected between 7:30-10:00 a.m. via peripheral (primarily antecubital) venipuncture in an independent session closely following the IPFU-2 and IPFU-3 sessions from consenting participants in serum and plasma tubes. Samples were not obtained from any participants reporting acute illness or injury. Samples were processed according to standard operating procedures before being stored at $-80^{\circ} \mathrm{C}$ (Tuck et al., 2009). Specifically, the serum samples used for our analyses were collected in red top silicon-coated tubes with no additives. Immediately following collection, tubes were kept upright for $40-60 \mathrm{~min}$ to allow for clot formation before being centrifuged (1300 g) for $20 \mathrm{~min}$ at room temperature. Immediately after, samples were

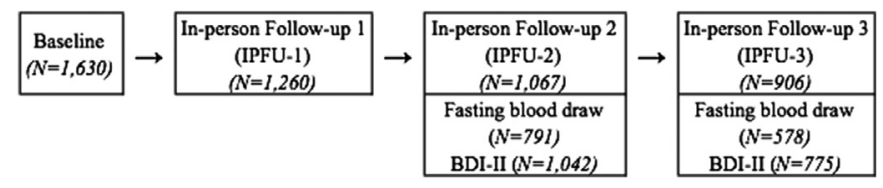

Fig. 1. A timeline of study assessments included in analyses. In-person followup visits (IPFU) were conducted approximately 2.5 years apart. Fasting blood draws were completed within two weeks of in-person follow-up visits. 
pipetted into 4-8 $2 \mathrm{~mL}$ tubes containing volumes of $500 \mu \mathrm{g}$ or $1 \mathrm{~mL}$ before being frozen at $-80^{\circ} \mathrm{C}$. Prior to analyses samples were removed from $-80^{\circ} \mathrm{C}$ and thawed at room temperature for $45 \mathrm{~min}$ on a nutating mixer. Samples were then centrifuged for $2 \mathrm{~min}$ at $3260 \times g$ to draw contaminants to the bottom of the tube. All reagents and samples were allowed to reach room temperature before use.

IL-6, CRP, and TNF $\alpha$ were assayed from serum in duplicate using commercially available enzyme-linked immunosorbent assays (IL-6: Quantikine HS Human IL-6, R\&D Systems, Minneapolis, MN, USA; CRP: EIA-3954 High Sensitivity C-Reactive Protein ELISA DRG International Inc., USA; TNF $\alpha$ : Quantikine HS Human IL-6, R\&D Systems, Minneapolis, $\mathrm{MN}, \mathrm{USA})$. Intra- and inter-assay coefficients of variation were acceptable (intra-assay CVs all $<8 \%$, inter-assay CVs all $<14 \%$ ). Samples producing unreliable measures (i.e., intra-assay CVs $>20 \%$ ) of IL-6 (IPFU-2: $N=38$; 4.8\% IPFU-3: $N=7 ; 1.19 \%$ ), CRP (IPFU-2: $N=22 ; 2.8 \%$; IPFU-3: $N=1$; $0.2 \%$ ), or TNF $\alpha$ (IPFU-2: $N=57 ; 8.7 \%$; IPFU-3: $N=4 ; 0.7 \%$ ), even after being re-assayed in duplicate were excluded (Table 1). Inflammation markers (i.e., IL-6, CRP, and TNF $\alpha$ ) were log transformed prior to analyses. Due to lack of consistency in results across inflammatory markers according to meta-analyses, we examined these markers independently, as opposed to forming an inflammatory index (Baumeister et al., 2016).

\subsubsection{Depressive symptoms}

The 21-item Beck Depression Inventory II (BDI-II; Beck et al., 1996) was used to assess the severity of current depressive symptoms. The BDI-II is rated on a 4-point, Likert-type scale ranging from 0 to 3 . Data from IPFU-2 $(M=5.32 \pm 6.397, N=707$, range $=0-45$, Cronbach's $\alpha=$ $0.90)$ and IPFU-3 $(M=5.59 \pm 6.781, N=485$, range $=0-54$, Cronbach's $\alpha=0.92$ ) from participants who had available inflammation data were used in analyses.

\subsection{Covariates}

Age. Participant age at the initial blood draw session was calculated using the participants' date of birth and the date of their blood draw appointment $(M=65.92 \pm 2.89, N=791$, range $=60-72)$.

Sex. Participant self-reported sex was recorded at the initial study baseline assessment $\left(N_{\text {female }}=392\right)$.

Race/Ethnicity. Two non-exclusive dummy-coded dichotomous variables were used to represent self-reported race and ethnicity as White/not White ${ }^{1}$ and Hispanic/not Hispanic, respectively $\left(N_{\text {White }}=\right.$ $\left.528 ; N_{\text {Hispanic }}=17\right)$.

Socioeconomic Status. Socioeconomic status (SES) was assessed using a composite score of participants' standardized self-reported education level, participants' parental education, and household annual

Table 1

Mean concentrations of IL-6, CRP, and TNF $\alpha$.

\begin{tabular}{lllllll}
\hline & IPFU-2 & & & \multicolumn{2}{l}{ IPFU-3 } & \multirow{2}{*}{ Sensitivity } \\
\cline { 2 - 3 } & M & N & & M & N & \\
\hline IL-6 & 0.259 & 753 & & 0.274 & 578 & $0.11 \mathrm{pg} / \mathrm{mL}$ \\
CRP & 0.409 & 769 & & 0.148 & 533 & $0.10 \mathrm{mg} / \mathrm{L}$ \\
TNF $\alpha$ & 0.150 & 650 & & 0.110 & 539 & $0.049 \mathrm{pg} / \mathrm{mL}$ \\
\hline
\end{tabular}

Note. Mean concentrations (winsorized and log-transformed) for IL-6 (pg/mL), $\mathrm{CRP}(\mathrm{mg} / \mathrm{L})$, and TNF $\alpha(\mathrm{pg} / \mathrm{mL})$ from blood collected at baseline and follow-up site visits.

\footnotetext{
1 As the sample was predominantly White and Black, one single dichotomous variable was used. Coding additional variables (e.g., White/not White, Black/ not Black) resulted in collinear covariates.
}

income level at the baseline interview $(M=0.11 \pm 0.845, N=722$, range $=-2-2$ ).

Body Mass Index. Body Mass Index (BMI) was calculated from participant height and weight, which were measured at blood draw $(M=$ $30.33 \pm 6.99, N=725$, range $=15-70)$.

Mean Arterial Pressure. Mean Arterial Pressure (MAP) was measured directly at the blood draw appointment via inflatable blood pressure cuff $(M=102.63 \pm 13.826, N=702$, range $=66-160)$.

Medication. Medication use was assessed using lists of all current prescription drugs, over the counter medications, and supplements provided by participants at the IPFU-2 interview and phlebotomy session. Medications were logged within the following medication classes as dummy-coded variables: beta blocker $(N=148)$, calcium blocker $(N=$ 144), statins $(N=261)$, ACE inhibitor $(N=257)$, benzodiazepines $(N=$ 43), hormonal medications $(N=60)$, aspirin $(N=256)$, prescription pain killer $(\mathrm{N}=84)$, non-steroidal anti-inflammatory drugs (NSAIDs; $N=$ 134), steroid medication $(N=94)$, antidepressant medication (i.e., a TCA, SSRI, or SNRI; $N=153$ ).

Sleep. Average hours of sleep per night was assessed by participant self-report at the blood draw appointment $(M=6.80 \pm 1.301, N=628$, range $=4-10$ ).

Caffeine. Average caffeine consumption (i.e., number of caffeinated beverages consumed in the average day) was assessed by participant selfreport at the blood draw appointment $(M=2.25 \pm 1.67, N=628$, range $=0-6)$.

Physical health. Physical health was assessed using participants' selfreported answers to the RAND-36 Health Status Inventory (Hays and Morales, 2001) at the IPFU-2 interview. A physical health component score was comprised of the Physical Functioning (PF), Role Limitations due to physical health (RLP), Pain (PA), and General Health (GHP) questions $(M=59.89 \pm 9.533, N=705$, range $=31-74$, Cronbach's $\alpha=$ 0.93).

\subsection{Statistical analyses}

To maintain data variability but minimize the influence of extreme outliers, outlier values on depression and inflammatory variables were winsorized to \pm 3 standard deviations before conducting analyses. Results were largely consistent when using raw values and excluding extreme outliers (see Supplement for more information). We examined associations between inflammatory markers and depressive symptoms using a three-step analytic procedure. First, we tested cross-sectional and prospective correlations between inflammation (i.e., IL-6, CRP, TNF $\alpha$ measured at IPFU-2 and IPFU-3) and depressive symptoms (measured at IPFU-2 and IPFU-3) without the inclusion of any covariates. We adjusted for multiple testing using Benjamini Hochberg false discovery rate correction ( $\left(\mathrm{fdr}_{\mathrm{BH}}\right.$ ) for 12 tests (i.e., IL-6, CRP, TNF $\alpha$ at 2 time points with depressive symptoms at 2 time points). Second, for any prospective associations between inflammatory markers and depressive symptoms (i.e., IPFU-2 being associated with IPFU-3) that were significant after multiple testing correction, we used a SEM framework to simultaneously examine concurrent and prospective relationships between each inflammatory marker and depression. Model fit was estimated by the chi-square estimate of goodness of fit, comparative fit index (CFI), root mean square error of approximation (RMSEA), and standardized root mean square residual (SRMR). All indices suggested good model fit. Finally, we tested whether associations were robust to the inclusion of potentially confounding covariates. Here, in a series of linear regressions, we entered all covariates described above (i.e., age at blood draw, sex, race, BMI, MAP, medication usage, sleep, caffeine, physical health and SES, see covariate section) as well as the outcome variable assessed at IPFU-2, before examining the association between the variables of interest (i.e., inflammation and depressive symptoms predicting one another at IPFU-2 and IPFU-3). All analyses were carried out using R Statistical Software (SEM analyses conducted using lavaan package). 


\section{Results}

\subsection{Correlations between measures over time}

Bivariate correlations between inflammation measures (i.e. IL-6, CRP, $\mathrm{TNF} \alpha$ ) from IPFU-2 and IPFU-3 are shown in Table 2. Each inflammatory marker showed moderate correlation over time (IL-6: $r=0.51$, CRP: $r=$ 0.59 , TNF $\alpha: r=0.44$ ) with evidence of correlation across markers, with the exception of CRP and TNF $\alpha$ (see Table 2). Self-reported depressive symptoms were highly correlated over time $(r=0.72)$.

\subsection{Inflammation and depression}

Correlational Analyses. Inflammatory markers (i.e., IL-6, CRP, TNF $\alpha$ ) assessed at each time point were significantly coupled with depressive symptoms measured at the same time ( $r s=0.09-0.22$; all $p s<0.05$; all $p_{f d r} s<0.054$; Table 2), with the exception of TNF $\alpha$ and depressive symptoms measured at IPFU-3 $\left(r=0.05 ; p=0.22 ; p_{f d r}=0.24\right)$.

CRP, IL-6, and TNF $\alpha$ measured at IPFU-2 were each significantly associated with subsequent depressive symptoms at IPFU-3 ( $r$ s = $0.12-0.22$; all $p s<0.01$; all $p_{f d r} s<0.02$; Table 2; Fig. 2). Depressive symptoms measured at IPFU-2 were significantly correlated with subsequent IL-6 levels at IPFU-3 $\left(r=0.09, p=0.017, p_{f d r}=0.030\right)$, but relationships with CRP or TNF $\alpha$ did not reach statistical significance ( $r \mathrm{~s}<$ $0.07, p s>0.2$; all $p_{f d r} s>0.24$; Table 2; Fig. 2).

SEM Analyses. In the model for IL-6, higher levels of IL-6 at IPFU-2 were prospectively associated with higher levels of depressive symptoms ( $\beta=0.089, p=0.008, N=463$ ), while depressive symptoms at IPFU-2 were not significantly associated with later levels of IL-6 ( $\beta=$ $0.013, p=0.748, N=463$ ). Similar results were found for CRP such that CRP at IPFU-2 was significantly associated with later depressive symptoms ( $\beta=0.090, p=0.007, N=433$ ), but the inverse was not significant $(\beta=-0.044, p=0.263, N=433)$. Finally, the model for TNF $\alpha$ indicated that neither prospective relationship was significant $(\beta s<0.04, p s>$ $0.23, N=379$ ).

Linear Regression Analyses. Regression analyses including demographic, behavioral, and medication covariates, as well as prior depressive symptoms and physical health symptoms (measured at IPFU2), revealed that IL-6 and CRP, but not TNF $\alpha$ (measured at IPFU-2), were independently associated with future depressive symptoms (measured at IPFU-3; Table 3; IL-6: $\beta=0.080, p=0.036, N=445$; CRP: $\beta=0.083, p=$ $0.030, N=457$; TNF $\alpha$ : $\beta=0.039, p=0.314, N=391$ ). There was no evidence that depressive symptoms at IPFU-2 were associated with later inflammatory markers after accounting for IPFU-2 levels of inflammation and other covariates (Table 4; all $\beta \mathrm{s}=-0.12$ to -0.006 , all $p \mathrm{~s}>0.05, \mathrm{Ns}$ $=327-457$ ).

\section{Discussion}

The current study examined the longitudinal relationship between inflammation markers and depressive symptoms at two time points approximately 2 years apart. Two primary findings emerged. First, consistent with a wealth of cross-sectional research (Bremmer et al., 2008; Danner et al., 2003; Dowlati et al., 2010; Wium-Andersen et al., 2013), we found that CRP and IL-6, but not TNF $\alpha$, were associated with concurrently measured depressive symptoms. Second, and most interestingly, both CRP and IL-6 prospectively predicted future depressive symptoms, even after accounting for depression at baseline. However, depression did not prospectively predict inflammation. Collectively, these data contribute to a developing literature showing that depression and inflammation are correlated and add temporal plausibility to speculation that inflammation may contribute to the development of depression, but that depression may not independently contribute to inflammation, at least in older age.

\subsection{Inflammation is prospectively associated with depression}

Elevated inflammatory cytokines have been associated with subsequent increases in depressive symptoms (Smith et al., 2018; Valkanova et al., 2013). Other studies have found that depression predicts future inflammation (e.g., Stewart et al., 2009) or failed to find any association (Forti et al., 2010) when considering a host of medical and psychosocial covariates. In the current study, cross-sectional analyses revealed associations between inflammatory markers and depressive symptoms at each timepoint. Moreover, our longitudinal findings support the former studies by demonstrating that inflammatory markers were associated with future depressive symptoms, even while controlling for initial depression levels (Table 3). Interestingly, TNF $\alpha$ was not significantly associated with future depression. Some studies have found elevated $\mathrm{TNF} \alpha$ in individuals with major depression compared to controls (Haapakoski et al., 2015), and that TNF $\alpha$ inhibition can improve depressive-like behavior in non-human animal models (Kaster et al., 2012) and in clinical trials (Raison et al., 2013). However, other studies (Mac Giollabhui et al., 2020; but see also Moriarity et al., 2020), much like ours have failed to identify an association. It is possible that these equivocal findings may be attributable to variability in methodology and participants as well as consideration of confounds. Indeed, when not considering covariates we did find hypothesized correlations between $\mathrm{TNF} \alpha$ and depression in some of our analyses.

Although prior work has found that depression predicts future inflammation (Mac Giollabhui et al., 2020), the current study failed to find such a relationship with any of the inflammatory makers examined. Of note, the current study's sample of older adults was demographically

Table 2

Bivariate correlations between inflammation measures and beck depression inventory at in-person follow up 2 (IPFU-2) and at in-person follow up 3 (IPFU-3).

\begin{tabular}{|c|c|c|c|c|c|c|c|c|}
\hline & IL-6 at IPFU-2 & CRP at IPFU-2 & TNF $\alpha$ at IPFU-2 & IL-6 at IPFU-3 & CRP at IPFU-3 & TNF $\alpha$ at IPFU-3 & BDI-II at IPFU-2 & BDI-II at IPFU-3 \\
\hline CRP at IPFU-2 & $\begin{array}{l}0.54 * * * \\
(N=739)\end{array}$ & - & - & - & - & - & - & - \\
\hline TNF $\boldsymbol{\alpha}$ at IPFU-2 & $\begin{array}{l}0.29 * * * \\
(N=622)\end{array}$ & $\begin{array}{l}0.16 * * * \\
(N=637)\end{array}$ & - & - & - & - & - & - \\
\hline IL-6 at IPFU-3 & $\begin{array}{l}0.51 * * * \\
(N=492)\end{array}$ & $\begin{array}{l}0.35^{* * *} \\
(N=499)\end{array}$ & $\begin{array}{l}0.19^{* * *} \\
(N=429)\end{array}$ & - & - & - & - & - \\
\hline CRP at IPFU-3 & $\begin{array}{l}0.30^{* * * *} \\
(N=452)\end{array}$ & $\begin{array}{l}0.59 * * * \\
(N=461)\end{array}$ & $\begin{array}{l}0.06 \\
(N=405)\end{array}$ & $\begin{array}{l}0.48^{* * *} \\
(N=511)\end{array}$ & - & - & - & - \\
\hline TNF $\alpha$ at IPFU-3 & $\begin{array}{l}0.13^{* *} \\
(N=458)\end{array}$ & $\begin{array}{l}0.02 \\
(N=467)\end{array}$ & $\begin{array}{l}0.44^{* * *} \\
(N=398)\end{array}$ & $\begin{array}{l}0.26^{* * *} \\
(N=513)\end{array}$ & $\begin{array}{l}0.09 * \\
(N=497)\end{array}$ & - & - & - \\
\hline BDI-II at IPFU-2 & $\begin{array}{l}0.22^{* * *} \\
(N=735)\end{array}$ & $\begin{array}{l}0.13^{* * * *} \\
(N=751)\end{array}$ & $\begin{array}{l}.09 * \\
(N=640)\end{array}$ & $\begin{array}{l}0.09^{*} \\
(N=552)\end{array}$ & $\begin{array}{l}0.06 \\
(N=509)\end{array}$ & $\begin{array}{l}-0.02 \\
(N=515)\end{array}$ & - & - \\
\hline BDI-II at IPFU-3 & $\begin{array}{l}0.22 * * * \\
(N=548)\end{array}$ & $\begin{array}{l}0.17^{* * *} \\
(N=559)\end{array}$ & $\begin{array}{l}0.13^{* * *} \\
(N=478)\end{array}$ & $\begin{array}{l}0.13^{*} \\
(N=547)\end{array}$ & $\begin{array}{l}0.09 * \\
(N=505)\end{array}$ & $\begin{array}{l}0.05 \\
(N=513)\end{array}$ & $\begin{array}{l}0.72^{* * *} \\
(N=720)\end{array}$ & - \\
\hline Mean \pm SD & $0.262 \pm 0.303$ & $0.414 \pm 0.530$ & $0.152 \pm 0.223$ & $0.277 \pm 0.300$ & $0.152 \pm 0.466$ & $0.112 \pm 0.188$ & $5.101 \pm 5.777$ & $5.505 \pm 5.979$ \\
\hline Range & $-0.54-1.96$ & $-1.23-2.15$ & $-0.6-1.50$ & $-0.57-1.69$ & $-1.35-1.81$ & $-1.10-1.02$ & $0-24.89$ & $0-25.98$ \\
\hline
\end{tabular}

* indicates that $p<0.05, * *$ indicates that $p<0.01, * * *$ indicates that $p<0.001$. All values are winsorized and inflammatory markers were log-transformed. 


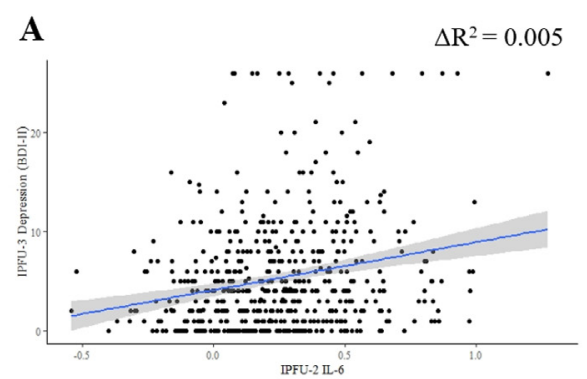

D

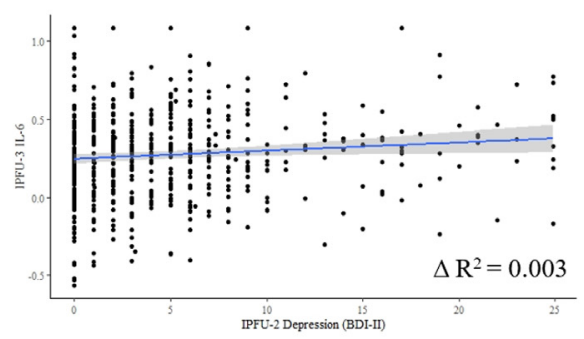

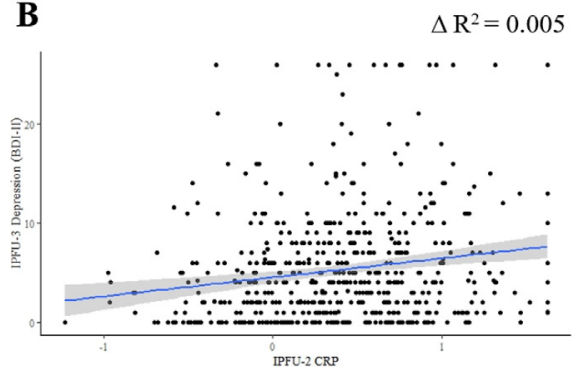
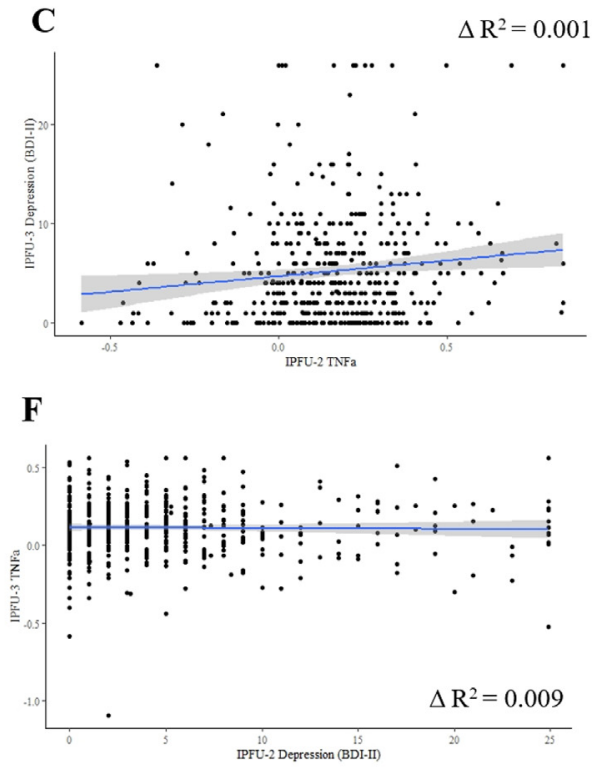

Fig. 2. Correlations between inflammatory markers (winsorized and log-transformed) and depressive symptoms (winsorized) at IFPU-2 and IPFU-3.

similar to other studies that also failed to find evidence that depression temporally precedes inflammation (Au et al., 2015; Gimeno et al., 2009; van den Biggelaar et al., 2007; Zalli et al., 2016). Alongside this literature, and meta-analytic evidence that depression precedes greater inflammation (Mac Giollabhui et al., 2020), our data raise the intriguing possibility that elevations in inflammation preceded by depression may be age dependent. Indeed, as aging is associated with increased inflammation (Alexopoulos and Morimoto, 2011; Franceschi and Campisi, 2014), there may be less contribution of depression-related factors (e.g., smoking, poor exercise) that influence subsequent inflammation (Ironson et al., 2018; Raposa et al., 2014). Alternatively, physical health conditions, which become increasing prominent in later life, represent a compelling putative mechanism through which depression may be related to inflammation, particularly in older age (Gorska-Ciebiada et al., 2015; Maggio et al., 2006; Stuart and Baune, 2012; Tracy, 2003). As such our null association between depression and future inflammation may be attributable to our inclusion of physical health as a covariate. However, if we remove physical health as a covariate in our model, we still fail to find that depression is predictive of future inflammation. ${ }^{2}$ Speculatively, it may be that inflammation is more strongly predictive of future depressive symptoms as individuals progress into old age and also experience age-related increases in inflammation (Alexopoulos and Morimoto, 2011; Franceschi and Campisi, 2014; Mac Giollabhui et al., 2020), Consistent with this notion, a recent meta-analysis found the link between CRP and future depression was greater in older individuals (Mac Giollabhui et al., 2020). On the other hand, depression-related increases in later inflammation may be more pronounced in younger life, when potential consequences of depression (e.g., smoking, poor exercise) may more prominently contribute to variability in inflammation (Ironson et al., 2018; Raposa et al., 2014).

\subsection{Limitations}

Limitations of the current study are important to consider. First, subject attrition between assessments may bias our results. Indeed, participants who did not have complete data had higher levels of baseline depression, IL-6, and CRP compared to those included in respective an-

\footnotetext{
${ }^{2}$ Depression predicting later inflammation excluding self-reported physical health and medication usage:.IL-6: $\beta=0.053, p=0.235$; CRP: $\beta=-0.035, p=$ 0.423; TNF $\alpha$ : $\beta=-0.064, p=0.219$.
}

alyses; as such, it is plausible that attribution related reductions on these variables attenuated our observed effects. Second, we measured depressive symptoms using a self-report questionnaire. As the relationship between depression and physical health outcomes is strongest when clinical levels of depression are assessed using clinical interview (Van der Kooy et al., 2007), future studies may benefit from the use of clinician-administered interviews. Third, we evaluated prospective relationships across two timepoints and during older age only. The relationship between inflammation and depression is likely dynamic and may vary across the lifespan, making it important for longer longitudinal studies with multiple timepoints of assessment. Fourth, we constrained our analyses to three commonly studied inflammatory markers; it will be important for future studies to move beyond CRP, IL- 6 and TNF $\alpha$ to study other inflammatory markers (e.g., IL-1 $\beta$, IL-8, IL-10) that can be reliably assayed and may play important additive or unique roles. Relatedly, it may be important to understanding inflammation in the context of interacting systems (e.g., glucocorticoid receptor-induced gene transcription). Finally, several potentially related factors were not considered in the current study, including the impact of stress, substance use, and social isolation on both depression and inflammation, which may play prominent roles in these relationships. Notably, unlike prior research, the current study found no association between BMI, sex, and SES and inflammation when including all covariates in regression models (Tables 3-4). However, there are significant bivariate correlations between inflammatory markers and these variables. ${ }^{3}$ The inclusion of physical health and medications as covariates may yield these associations non-significant (Tables 3-4).

\section{Conclusion and future directions}

In a community sample of older individuals, we found that CRP and IL-6, but not TNF $\alpha$, were prospectively associated with later depressive

\footnotetext{
${ }^{3}$ BMI was correlated with inflammatory markers at IPFU2 (IL-6: $r=0.32, p<$ 0.001; CRP: 0.42, $p<0.001$; and TNF $\alpha: r=0.11, p=0.007$ ) and IPFU-3 (IL-6: $r$ $=0.30, p<0.001$; CRP: $r=0.30, p<0.001$; TNF $\alpha: r=0.14, p=0.0013)$. SES was correlated with IL-6 and CRP at IPFU-2 (IL-6: $r=-0.24, p<0.001$; CRP: $r$ $=-0.24, p<0.001$ ) and IPFU-3 (IL-6: $r=-0.19, p<0.001$; CRP $r=-0.17, p$ $<0.001$ ) but not TNF $\alpha$ at either timepoint (rs $<0 .-0.03$, ps $>0.05$ ). Sex was only associated with CRP at IPFU-2 $(r=0.15, p<0.001)$ and IPFU-3 $(r=0.12$, $p=0.008)$ and TNF $\alpha$ at IPFU-2 $(r=-0.10, p=0.011)$.
} 
Table 3

Regression analyses for inflammatory markers at IPFU-2 predicting depression (BDI-II) at IPFU-3.

\begin{tabular}{|c|c|c|c|c|c|c|c|c|c|c|c|c|c|c|c|}
\hline & \multicolumn{15}{|c|}{ Inflammatory Markers } \\
\hline & \multicolumn{5}{|c|}{$\mathrm{IL}-6(\mathrm{~N}=445)$} & \multicolumn{5}{|c|}{ CRP $(\mathrm{N}=457)$} & \multicolumn{5}{|c|}{$\mathrm{TNF} \boldsymbol{\alpha}(\mathrm{N}=391)$} \\
\hline & B & SE B & $\beta$ & $\mathrm{p}$ & CI (95\%) & B & SE B & $\beta$ & $\mathrm{p}$ & CI (95\%) & B & SE B & $\beta$ & $\mathrm{p}$ & CI (95\%) \\
\hline Age & 0.131 & 0.071 & 0.064 & 0.065 & $-0.008,0.270$ & 0.103 & 0.070 & 0.050 & 0.140 & $-0.034,0.240$ & 0.139 & 0.075 & 0.069 & 0.067 & $-0.009,0.287$ \\
\hline Gender & -0.510 & 0.428 & -0.043 & 0.234 & $-1.352,0.332$ & -0.710 & 0.422 & -0.060 & 0.094 & $-1.540,0.120$ & -0.940 & 0.450 & -0.081 & 0.037 & $-1.824,-0.056$ \\
\hline Race & 0.758 & 0.540 & 0.054 & 0.162 & $-0.305,1.820$ & 0.870 & 0.529 & 0.064 & 0.100 & $-0.169,1.909$ & 0.301 & 0.569 & 0.023 & 0.597 & $-0.819,1.421$ \\
\hline Ethnicity & 0.827 & 1.278 & 0.022 & 0.518 & $-1.685,3.339$ & 1.032 & 1.268 & 0.027 & 0.416 & $-1.459,3.523$ & 1.660 & 1.413 & 0.043 & 0.241 & $-1.119,4.439$ \\
\hline SES & -0.334 & 0.264 & -0.047 & 0.207 & $-0.854,0.185$ & -0.386 & 0.260 & -0.055 & 0.138 & $-0.897,0.125$ & -0.375 & 0.286 & -0.054 & 0.191 & $-0.938,0.188$ \\
\hline BMI & -0.041 & 0.033 & -0.051 & 0.206 & $-0.105,0.023$ & -0.066 & 0.034 & -0.081 & 0.053 & $-0.132,0.001$ & -0.022 & 0.033 & -0.029 & 0.501 & $-0.088,0.043$ \\
\hline Physical Health & -0.095 & 0.030 & -0.148 & 0.002 & $-0.154,-0.035$ & -0.103 & 0.030 & -0.162 & 0.001 & $-0.163,-0.044$ & -0.065 & 0.032 & -0.104 & 0.043 & $-0.128,-0.002$ \\
\hline MAP & -0.013 & 0.015 & -0.031 & 0370 & $-0.043,0.016$ & -0.006 & 0.015 & -0.016 & 0.654 & $-0.036,0.022$ & -0.015 & 0.016 & -0.036 & 0.336 & $-0.047,0.016$ \\
\hline Beta Blockers & -0.571 & 0.512 & -0.039 & 0.265 & $-1.577,0.435$ & -0.378 & 0.503 & -0.026 & 0.453 & $-1.367,0.611$ & -0.575 & 0.550 & -0.040 & 0.297 & $-1.656,0.507$ \\
\hline Calcium Blockers & 0.354 & 0.523 & 0.024 & 0.499 & $-0.675,1.383$ & 0.553 & 0.510 & 0.039 & 0.279 & $-0.450,1.555$ & 0.591 & 0.542 & 0.042 & 0.276 & $-0.475,1.658$ \\
\hline Statins & 0.751 & 0.454 & 0.060 & 0.099 & $-0.142,1.644$ & 1.005 & 0.445 & 0.082 & 0.028 & $0.131,1.879$ & 0.639 & 0.485 & 0.052 & 0.188 & $-0.314,1.593$ \\
\hline ACE Inhibitors & -0.349 & 0.476 & -0.028 & 0.464 & $-1.284,0.587$ & -0.443 & 0.465 & -0.036 & 0.340 & $-1.357,0.470$ & -0.386 & 0.506 & -0.031 & 0.445 & $-1.381,0.608$ \\
\hline Benzodiazepines & 1.172 & 0.910 & 0.045 & 0.199 & $-0.617,2.962$ & 0.907 & 0.865 & 0.035 & 0.312 & $-0.853,2.667$ & 1.070 & 0.939 & 0.044 & 0.255 & $-0.776,2.917$ \\
\hline Hormones & 0.305 & 0.719 & 0.014 & 0.672 & $-1.108,1.717$ & 0.592 & 0.710 & 0.028 & 0.405 & $-0.805,1.988$ & -0.150 & 0.783 & 0.007 & 0.848 & $-1.690,1.390$ \\
\hline Aspirin & -0.771 & 0.445 & -0.063 & 0.084 & $-1.645,0.104$ & -1.059 & 0.434 & -0.087 & 0.015 & $-1.911,-0.207$ & -0.736 & 0.464 & -0.062 & 0.114 & $-1.645,0.178$ \\
\hline Pain Medication & -1.636 & 0.671 & -0.090 & 0.015 & $-2.956,-0.316$ & -1.198 & 0.647 & -0.068 & 0.065 & $-2.469,-0.073$ & -1.557 & 0.674 & -0.090 & 0.021 & $-2.882,-0.232$ \\
\hline NSAID & 0.160 & 0.530 & 0.010 & 0.763 & $-0.882,1.202$ & 0.101 & 0.517 & 0.007 & 0.846 & $-0.915,1.117$ & -0.408 & 0.549 & -0.028 & 0.6458 & $-1.488,0.672$ \\
\hline Steroids & 1.230 & 0.600 & 0.070 & 0.041 & $-0.052,2.409$ & 1.006 & 0.600 & 0.057 & 0.095 & $-0.174,2.185$ & 0.932 & 0.649 & 0.053 & 0.152 & $-0.345,2.210$ \\
\hline Anti-depressants & 1.568 & 0.561 & 0.105 & 0.005 & $0.465,2.671$ & 1.401 & 0.550 & 0.094 & 0.011 & $0321,2.481$ & 1.999 & 0.597 & 0.136 & $<0.001$ & $0.825,3.172$ \\
\hline Sleep & -0.045 & 0.168 & -0.010 & 0.790 & $-0.375,0.285$ & -0.036 & 0.165 & -0.008 & 0.82 & $-0.361,0.289$ & -0.075 & 0.183 & -0.016 & 0.681 & $-0.435,0.285$ \\
\hline Caffeine & -0.167 & 0.122 & -0.048 & 0.168 & $-0.407,0.071$ & -0.099 & 0.122 & -0.028 & 0.415 & $-0.339,0.140$ & -0.082 & 0.134 & -0.023 & 0.541 & $-0.344,0.181$ \\
\hline BDI-II at IPFPU-2 & 0.611 & 0.045 & 0.563 & $<0.001$ & $0.522,0.700$ & 0.606 & 0.045 & 0.564 & $<0.001$ & $0.518,0.693$ & 0.619 & 0.049 & 0.586 & $<0.001$ & $0.523,0.715$ \\
\hline Inflammation at IPFU-2 & 1.758 & 0.835 & 0.080 & 0.036 & $0.116,3.400$ & 0.935 & 0.429 & 0.083 & 0.030 & $0.095,1.778$ & 1.049 & 1.041 & 0.039 & 0.314 & $-0.998,3.097$ \\
\hline
\end{tabular}


Table 4

Regression analyses for depression (BDI-II) at IPFU-2 predicting inflammation at IPFU-3.

\begin{tabular}{|c|c|c|c|c|c|c|c|c|c|c|c|c|c|c|c|}
\hline & \multicolumn{15}{|c|}{ Inflammatory Markers } \\
\hline & \multicolumn{5}{|c|}{$\mathrm{IL}-6(\mathrm{~N}=404)$} & \multicolumn{5}{|c|}{$\operatorname{CRP}(\mathrm{N}=378)$} & \multicolumn{5}{|c|}{$\mathrm{TNF} \boldsymbol{\alpha}(\mathrm{N}=327)$} \\
\hline & B & SE B & $\beta$ & $p$ & CI (95\%) & B & SE B & $\beta$ & $p$ & CI (95\%) & B & SE B & $\beta$ & $p$ & CI (95\%) \\
\hline Age & 0.010 & 0.004 & 0.099 & 0.024 & $0.001,0.018$ & 0.004 & 0.007 & 0.029 & 0.506 & $-0.009,0.018$ & 0.006 & 0.003 & 0.093 & 0.082 & $-0.001,0.012$ \\
\hline Gender & -0.009 & 0.026 & -0.016 & 0.726 & $-0.061,0.043$ & 0.038 & 0.043 & 0.041 & 0.377 & $-0.046,0.123$ & 0.016 & 0.020 & 0.043 & 0.443 & $-0.024,0.055$ \\
\hline Race & -0.049 & 0.033 & -0.076 & 0.137 & $-0.115,0.016$ & -0.063 & 0.055 & -0.059 & 0.256 & $-0.171,0.046$ & 0.004 & 0.026 & 0.010 & 0.870 & $-0.047,0.056$ \\
\hline Ethnicity & -0.022 & 0.079 & -0.012 & 0.778 & $-0.177,0.132$ & -0.068 & 0.124 & -0.023 & 0.586 & $-0.312,0.176$ & 0.026 & 0.064 & 0.022 & 0.689 & $-0.100,0.151$ \\
\hline SES & -0.011 & 0.016 & -0.032 & 0.502 & $-0.043,0.021$ & -0.023 & 0.026 & -0.042 & 0.385 & $-0.075,0.029$ & -0.004 & 0.013 & -0.017 & 0.777 & $-0.029,0.022$ \\
\hline BMI & 0.003 & 0.002 & 0.082 & 0.111 & $-0.001,0.007$ & 0.002 & 0.004 & 0.035 & 0.513 & $-0.005,0.010$ & 0.001 & 0.002 & 0.021 & 0.728 & $-0.002,0.004$ \\
\hline Physical Health & -0.004 & 0.002 & -0.121 & 0.047 & $-0.007,0.000$ & -0.001 & 0.003 & -0.030 & 0.621 & $-0.007,0.004$ & -0.002 & 0.001 & -0.091 & 0.211 & $-0.005,0.001$ \\
\hline MAP & 0.001 & 0.001 & 0.067 & 0.145 & $0.000,0.003$ & 0.003 & 0.002 & 0.088 & 0.064 & $0.000,0.006$ & $<0.001$ & 0.001 & 0.036 & 0.524 & $-0.001,0.002$ \\
\hline Beta Blockers & 0.016 & 0.031 & 0.023 & 0.605 & $-0.046,0.077$ & 0.035 & 0.052 & 0.031 & 0.497 & $-0.067,0.137$ & -0.006 & 0.025 & -0.014 & 0.798 & $-0.055,0.043$ \\
\hline Calcium Blockers & -0.003 & 0.031 & -0.004 & 0.922 & $-0.065,0.059$ & 0.002 & 0.052 & 0.002 & 0.964 & $-0.100,0.105$ & 0.006 & 0.025 & 0.014 & 0.801 & $-0.043,0.055$ \\
\hline Statins & $<0.001$ & 0.027 & $<0.001$ & 0.995 & $-0.054,0.054$ & -0.040 & 0.046 & -0.042 & 0.379 & $-0.130,0.050$ & -0.019 & 0.022 & -0.048 & 0.388 & $-0.061,0.024$ \\
\hline ACE Inhibitors & -0.049 & 0.029 & -0.082 & 0.087 & $-0.105,0.007$ & -0.013 & 0.047 & -0.013 & 0.781 & $-0.106,0.079$ & 0.014 & 0.023 & 0.035 & 0.553 & $-0.031,0.059$ \\
\hline Benzodiazepines & 0.012 & 0.054 & 0.011 & 0.817 & $-0.093,0.118$ & 0.088 & 0.088 & 0.045 & 0.322 & $-0.086,0.262$ & 0.032 & 0.044 & 0.042 & 0.458 & $-0.053,0.118$ \\
\hline Hormones & 0.029 & 0.045 & 0.029 & 0.515 & $-0.059,0.118$ & 0.041 & 0.079 & 0.023 & 0.609 & $-0.115,0.197$ & 0.047 & 0.037 & 0.067 & 0.209 & $-0.026,0.121$ \\
\hline Aspirin & -0.009 & 0.027 & -0.016 & 0.730 & $-0.062,0.044$ & 0.001 & 0.044 & 0.001 & 0.983 & $-0.086,0.088$ & 0.038 & 0.021 & 0.103 & 0.062 & $-0.002,0.080$ \\
\hline Pain Medication & 0.005 & 0.042 & 0.006 & 0.906 & $-0.078,0.088$ & -0.048 & 0.067 & -0.034 & 0.480 & $-0.180,0.085$ & -0.013 & 0.030 & -0.025 & 0.655 & $-0.072,0.040$ \\
\hline NSAID & 0.029 & 0.033 & 0.039 & 0.375 & $-0.035,0.093$ & 0.093 & 0.054 & 0.079 & 0.083 & $-0.012,0.198$ & -0.013 & 0.024 & -0.029 & 0.595 & $-0.061,0.035$ \\
\hline Steroids & 0.005 & 0.037 & 0.006 & 0.899 & $-0.070,0.077$ & -0.012 & 0.063 & -0.008 & 0.854 & $-0.136,0.112$ & -0.016 & 0.028 & -0.030 & 0.578 & $-0.072,0.040$ \\
\hline Anti-depressants & 0.031 & 0.035 & 0.045 & 0.368 & $-0.037,0.100$ & 0.037 & 0.058 & 0.032 & 0.522 & $-0.077,0.152$ & -0.002 & 0.027 & -0.003 & 0.955 & $-0.053,0.056$ \\
\hline Sleep & 0.005 & 0.010 & 0.024 & 0.618 & $-0.015,0.025$ & 0.005 & 0.017 & 0.014 & 0.773 & $-0.028,0.038$ & -0.003 & 0.008 & -0.019 & 0.750 & $-0.019,0.014$ \\
\hline Caffeine & 0.012 & 0.008 & 0.072 & 0.105 & $-0.003,0.027$ & 0.023 & 0.013 & 0.081 & 0.073 & $-0.002,0.048$ & -0.001 & 0.006 & -0.009 & 0.864 & $-0.013,0.011$ \\
\hline IL-6 at IPFPU-2 & 0.492 & 0.052 & 0.454 & $<0.001$ & $0.389,0.595$ & & & & & & & & & & \\
\hline CRP at IPFU-2 & & & & & & 0.530 & 0.046 & 0.558 & $<0.001$ & $0.441,0.620$ & & & & & \\
\hline TNF $\alpha$ at IPFU-2 & & & & & & & & & & & 0.346 & 0.048 & 0.405 & $<0.001$ & $0.251,0.440$ \\
\hline BDI-II at IPFU-2 & -0.003 & 0.003 & -0.064 & 0.227 & $-0.008,0.002$ & -0.007 & 0.004 & -0.090 & 0.095 & $-0.016,0.001$ & -0.004 & 0.002 & -0.121 & 0.067 & $-0.008,<0.001$ \\
\hline
\end{tabular}


symptoms. However, despite evidence from meta-analytic studies (Mac Giollabhui et al., 2020), we found no evidence that depression is associated with later inflammation. It is possible that during older age, as inflammation rises, its association with future depression is potentiated but that depression may only precede elevations in inflammation during younger ages, when depression-related behaviors may potentiate lower baseline levels of inflammation. These equivocal results may also reflect heterogeneity in depression and inflammation that suggest additional moderating and mediating factors should be considered (Raison et al., 2006). As such, future research will benefit from examining potential pathways that contribute to depression in the context of increased inflammation, such as stress exposure and reward-related behaviors (Slavich and Irwin, 2014; Treadway, 2016). Finally, inflammation represents a promising treatment target, at least in some cases. Studies have found evidence that inhibition of pro-inflammatory cytokines may have antidepressant effects (Köhler et al., 2014; Müller et al., 2006), and that inhibition of inflammation may especially benefit depressed patients with high baseline levels of inflammation biomarkers (Raison et al., 2013). Targeting inflammation to treat depression may be particularly beneficial to older adults.

\section{Funding}

Within the past three years MTT has received consulting fees from Avanir Pharmaceuticals and BlackThorn Therapeutics. No funding or sponsorship was provided by these companies for the current work, and all views expressed herein are solely those of the authors.

The authors wish to thank SPAN study participants, informants, and staff. The SPAN study is funded by R01-AG045231 and R01-AG061162. EB was supported by F31-MH123105. SN, MV, MB, TFO, and RB were supported by R01-AG045231 \& R01-AG061162. RB received additional support from R01-HD083614, R01-AG052564, R21-AA027827, R01DA046224, R56-AG059265, R34-DA050272, R01-AG061162 and the Klingenstein Third Generation Foundation.

\section{Declaration of competing interest}

None.

\section{Appendix A. Supplementary data}

Supplementary data to this article can be found online at https://do i.org/10.1016/j.bbih.2021.100226.

\section{References}

Alexopoulos, G.S., Morimoto, S.S., 2011. The inflammation hypothesis in geriatric depression. Int. J. Geriatr. Psychiatr. 26 (11), 1109-1118. https://doi.org/10.1002/ gps.2672.

Anisman, H., Merali, Z., Poulter, M.O., Hayley, S., 2005. Cytokines as a precipitant of depressive illness: animal and human studies. Curr. Pharmaceut. Des. 11 (8), 963-972. https://doi.org/10.2174/1381612053381701.

Au, B., Smith, K.J., Gariépy, G., Schmitz, N., 2015. The longitudinal associations between $\mathrm{C}$-reactive protein and depressive symptoms: evidence from the English Longitudinal Study of Ageing (ELSA). Int. J. Geriatr. Psychiatr. 30 (9), 976-984. https://doi.org/ 10.1002/gps.4250.

Baumeister, D., Akhtar, R., Ciufolini, S., Pariante, C.M., Mondelli, V., 2016. Childhood trauma and adulthood inflammation: a meta-analysis of peripheral C-reactive protein, interleukin-6 and tumour necrosis factor- $\alpha$. Mol. Psychiatr. 21 (5), 642-649. https://doi.org/10.1038/mp.2015.67.

Beck, A.T., Steer, R.A., Brown, G.K., 1996. Manual for the Beck Depression Inventory-II. Psychological Cooperation, San Antonio, TX.

Bremmer, M.A., Beekman, A.T.F., Deeg, D.J.H., Penninx, B.W.J.H., Dik, M.G., Hack, C.E., Hoogendijk, W.J.G., 2008. Inflammatory markers in late-life depression: results from a population-based study. J. Affect. Disord. 106 (3), 249-255. https://doi.org/ 10.1016/j.jad.2007.07.002.

Capuron, L., Ravaud, A., Miller, A.H., Dantzer, R., 2004. Baseline mood and psychosocial characteristics of patients developing depressive symptoms during interleukin-2 and/ or interferon-alpha cancer therapy. Brain Behav. Immun. 18 (3), 205-213. https:// doi.org/10.1016/j.bbi.2003.11.004.
Danner, M., Kasl, S.V., Abramson, J.L., Vaccarino, V., 2003. Association between depression and elevated C-reactive protein. Psychosom. Med. 65 (3), 347-356. https://doi.org/10.1097/01.PSY.0000041542.29808.01.

Dantzer, R., O'Connor, J.C., Freund, G.G., Johnson, R.W., Kelley, K.W., 2008. From inflammation to sickness and depression: when the immune system subjugates the brain. Nat. Rev. Neurosci. 9 (1), 46-56. https://doi.org/10.1038/nrn2297.

Dobos, N., de Vries, Kema, I.P., Patas, K., Prins, M., Nijholt, I.M., Dierckx, R.A., Korf, J., den Boer, Luiten, P.G.M., Eisel, U.L.M., 2012. The Role of Indoleamine 2,3-Dioxygenase in a Mouse Model of Neuroinflammation-Induced Depression. Journal of Alzheimer's Disease 28 (4), 905-915. https://doi.org/10.3233/JAD-2011-111097.

Dowlati, Y., Herrmann, N., Swardfager, W., Liu, H., Sham, L., Reim, E.K., Lanctôt, K.L., 2010. A meta-analysis of cytokines in major depression. Biol. Psychiatr. 67 (5), 446-457. https://doi.org/10.1016/j.biopsych.2009.09.033.

Ferrucci, L., Fabbri, E., 2018. Inflammaging: chronic inflammation in ageing, cardiovascular disease, and frailty. Nat. Rev. Cardiol. 15 (9), 505-522. https:// doi.org/10.1038/s41569-018-0064-2.

Fiske, A., Wetherell, J.L., Gatz, M., 2009. Depression in older adults. Annu. Rev. Clin. Psychol. 5, 363-389. https://doi.org/10.1146/annurev.clinpsy.032408.153621.

Forti, P., Rietti, E., Pisacane, N., Olivelli, V., Mariani, E., Chiappelli, M., Licastro, F., Ravaglia, G., 2010. Blood inflammatory proteins and risk of incident depression in the elderly. Dement. Geriatr. Cognit. Disord. 29 (1), 11-20. https://doi.org/10.1159/ 000261644.

Franceschi, C., Campisi, J., 2014. Chronic inflammation (inflammaging) and its potential contribution to age-associated diseases. J. Gerontol.: Ser. A 69 (Suppl. 1_1), S4-S9. https://doi.org/10.1093/gerona/glu057.

Franceschi, C., Garagnani, P., Vitale, G., Capri, M., Salvioli, S., 2017. Inflammaging and 'garb-aging. Trends Endocrinol. Metabol. 28 (3), 199-212. https://doi.org/10.1016/ j.tem.2016.09.005.

GBD 2017 Disease and Injury Incidence and Prevalence Collaborators, 2018. Global, regional, and national incidence, prevalence, and years lived with disability for 354 diseases and injuries for 195 countries and territories, 1990-2017: a systematic analysis for the Global Burden of Disease Study 2017. Lancet (London, England) 392 (10159), 1789-1858. https://doi.org/10.1016/S0140-6736(18)32279-7.

Gimeno, D., Kivimäki, M., Brunner, E.J., Elovainio, M., De Vogli, R., Steptoe, A., Kumari, M., Lowe, G.D.O., Rumley, A., Marmot, M.G., Ferrie, J.E., 2009. Associations of C-reactive protein and interleukin-6 with cognitive symptoms of depression: 12 year follow-up of the Whitehall II study. Psychol. Med. 39 (3), 413. https://doi.org/ 10.1017/S0033291708003723.

Gorska-Ciebiada, M., Saryusz-Wolska, M., Borkowska, A., Ciebiada, M., Loba, J., 2015. Serum levels of inflammatory markers in depressed elderly patients with diabetes and mild cognitive impairment. PloS One 10 (3). https://doi.org/10.1371/ journal.pone.0120433.

Grosse, L., Carvalho, L.A., Wijkhuijs, A.J.M., Bellingrath, S., Ruland, T., Ambrée, O., Alferink, J., Ehring, T., Drexhage, H.A., Arolt, V., 2015. Clinical characteristics of inflammation-associated depression: monocyte gene expression is age-related in major depressive disorder. Brain Behav. Immun. 44, 48-56. https://doi.org/ 10.1016/j.bbi.2014.08.004.

Haapakoski, R., Mathieu, J., Ebmeier, K.P., Alenius, H., Kivimäki, M., 2015. Cumulative meta-analysis of interleukins 6 and $1 \beta$, tumour necrosis factor $\alpha$ and C-reactive protein in patients with major depressive disorder. Brain Behav. Immun. 49, 206-215. https://doi.org/10.1016/j.bbi.2015.06.001.

Hannestad, J., DellaGioia, N., Bloch, M., 2011. The effect of antidepressant medication treatment on serum levels of inflammatory cytokines: a meta-analysis. Neuropsychopharmacology 36 (12), 2452-2459. https://doi.org/10.1038/ npp.2011.132.

Hays, R.D., Morales, L.S., 2001. The RAND-36 measure of health-related quality of life. Ann. Med. 33 (5), 350-357. https://doi.org/10.3109/07853890109002089.

Howren, M.B., Lamkin, D.M., Suls, J., 2009. Associations of depression with C-reactive protein, IL-1, and IL-6: A meta-analysis. Psychosomatic Medicine 71 (2), 171-186. https://doi.org/10.1097/PSY.0b013e3181907c1b.

Ironson, G., Banerjee, N., Fitch, C., Krause, N., 2018. Positive emotional well-being, health Behaviors, and inflammation measured by C-Reactive protein. Soc. Sci. Med. 197, 235-243. https://doi.org/10.1016/j.socscimed.2017.06.020.

Kaster, M.P., Gadotti, V.M., Calixto, J.B., Santos, A.R.S., Rodrigues, A.L.S., 2012. Depressive-like behavior induced by tumor necrosis factor- $\alpha$ in mice. Neuropharmacology 62 (1), 419-426. https://doi.org/10.1016/ j.neuropharm.2011.08.018.

Kiecolt-Glaser, J.K., Derry, H.M., Fagundes, C.P., 2015. Inflammation: depression fans the flames and feasts on the heat. Am. J. Psychiatr. 172 (11), 1075-1091. https:// doi.org/10.1176/appi.ajp.2015.15020152.

Kish, L., 1949. A procedure for objective respondent selection within the household. J. Am. Stat. Assoc. 44 (247), 380-387. https://doi.org/10.2307/2280236. JSTOR.

Köhler, O., Benros, M.E., Nordentoft, M., Farkouh, M.E., Iyengar, R.L., Mors, O., Krogh, J., 2014. Effect of anti-inflammatory treatment on depression, depressive symptoms, and adverse effects: a systematic review and meta-analysis of randomized clinical trials. JAMA Psychiatr. 71 (12), 1381. https://doi.org/10.1001/ jamapsychiatry.2014.1611.

Leonard, B.E., 2014. Impact of inflammation on neurotransmitter changes in major depression: an insight into the action of antidepressants. Prog. Neuro Psychopharmacol. Biol. Psychiatr. 48, 261-267. https://doi.org/10.1016/ j.pnpbp.2013.10.018.

Leonard, B.E., 2018. Inflammation and depression: a causal or coincidental link to the pathophysiology? Acta Neuropsychiatr. 30 (1), 1-16. https://doi.org/10.1017/ neu.2016.69. 
Liu, Y.-Z., Wang, Y.-X., Jiang, C.-L., 2017. Inflammation: The Common Pathway of StressRelated Diseases. Frontiers in Human Neuroscience 11. https://doi.org/10.3389/fnh um.2017.00316.

Mac Giollabhui, N., Ng, T.H., Ellman, L.M., Alloy, L.B., 2020. The longitudinal associations of inflammatory biomarkers and depression revisited: systematic review, meta-analysis, and meta-regression. Mol. Psychiatr. 1-13. https://doi.org/10.1038/ s41380-020-00867-4.

Maggio, M., Guralnik, J.M., Longo, D.L., Ferrucci, L., 2006. Interleukin-6 in aging and chronic disease: a magnificent pathway. J. Gerontol.: Ser. A 61 (6), 575-584. https:// doi.org/10.1093/gerona/61.6.575.

Miller, A.H., Maletic, V., Raison, C.L., 2009. Inflammation and its discontents: the role of cytokines in the pathophysiology of major depression. Biol. Psychiatr. 65 (9), 732-741. https://doi.org/10.1016/j.biopsych.2008.11.029.

Miller, A.H., Raison, C.L., 2016. The role of inflammation in depression: from evolutionary imperative to modern treatment target. Nat. Rev. Immunol. 16 (1), 22-34. https://doi.org/10.1038/nri.2015.5.

Moieni, M., Irwin, M.R., Jevtic, I., Olmstead, R., Breen, E.C., Eisenberger, N.I., 2015. Sex differences in depressive and socioemotional responses to an inflammatory challenge: implications for sex differences in depression. Neuropsychopharmacology 40 (7), 1709-1716. https://doi.org/10.1038/npp.2015.17.

Moreira, F.P., Cardoso, T. de A., Mondin, T.C., Souza, L.D. de M., Silva, R., Jansen, K., Oses, J.P., Wiener, C.D., 2015. The effect of proinflammatory cytokines in Cognitive Behavioral Therapy. J. Neuroimmunol. 285, 143-146. https://doi.org/10.1016/ j.jneuroim.2015.06.004.

Moriarity, D.P., Kautz, M.M., Giollabui, N.M., Klugman, J., Coe, C.L., Ellman, L.M., Abramson, L.Y., Alloy, L.B., 2020. Bidirectional associations between inflammatory biomarkers and depressive symptoms in adolescents: potential causal relationships. Clin. Psychol. Sci.: J. Asso. Psychol. Sci. 8 (4), 690-703. https://doi.org/10.1177/ 2167702620917458.

Müller, N., Schwarz, M.J., Dehning, S., Douhe, A., Cerovecki, A., Goldstein-Müller, B., Spellmann, I., Hetzel, G., Maino, K., Kleindienst, N., Möller, H.-J., Arolt, V., Riedel, M., 2006. The cyclooxygenase-2 inhibitor celecoxib has therapeutic effects in major depression: results of a double-blind, randomized, placebo controlled, add-on pilot study to reboxetine. Mol. Psychiatr. 11 (7), 680-684. https://doi.org/10.1038/ sj.mp. 4001805.

Oltmanns, T.F., Rodrigues, M.M., Weinstein, Y., Gleason, M.E.J., 2014. Prevalence of personality disorders at midlife in a community sample: disorders and symptoms reflected in interview, self, and informant reports. J. Psychopathol. Behav. Assess. 36 (2), 177-188. https://doi.org/10.1007/s10862-013-9389-7.

Raison, C.L., Capuron, L., Miller, A.H., 2006. Cytokines sing the blues: inflammation and the pathogenesis of depression. Trends Immunol. 27 (1), 24-31. https://doi.org/ 10.1016/j.it.2005.11.006.

Raison, C.L., Rutherford, R.E., Woolwine, B.J., Shuo, C., Schettler, P., Drake, D.F., Haroon, E., Miller, A.H., 2013. A randomized controlled trial of the tumor necrosis factor Antagonist infliximab for treatment-resistant depression: the role of baseline inflammatory biomarkers. JAMA Psychiatr. 70 (1), 31. https://doi.org/10.1001/ 2013.jamapsychiatry.4.

Raposa, E.B., Bower, J.E., Hammen, C.L., Najman, J.M., Brennan, P.A., 2014. A developmental pathway from early life stress to inflammation: the role of negative health behaviors. Psychol. Sci. 25 (6), 1268-1274. https://doi.org/10.1177/ 0956797614530570.

Reichenberg, A., Yirmiya, R., Schuld, A., Kraus, T., Haack, M., Morag, A., Pollmächer, T., 2001. Cytokine-associated emotional and cognitive disturbances in humans. Arch. Gen. Psychiatr. 58 (5), 445-452. https://doi.org/10.1001/archpsyc.58.5.445.
Ridker, P.M., 2007. C-reactive protein and the prediction of cardiovascular events among those at intermediate risk: Moving an inflammatory hypothesis toward consensus. Journal of the American College of Cardiology 49 (21), 2129-2138. https://doi.o $\mathrm{rg} / 10.1016 / \mathrm{j}$.jacc.2007.02.052.

Slavich, G.M., Irwin, M.R., 2014. From stress to inflammation and major depressive disorder: a social signal transduction theory of depression. Psychol. Bull. 140 (3), 774-815. https://doi.org/10.1037/a0035302.

Smith, K.J., Au, B., Ollis, L., Schmitz, N., 2018. The association between C-reactive protein, Interleukin- 6 and depression among older adults in the community: a systematic review and meta-analysis. Exp. Gerontol. 102, 109-132. https://doi.org/ 10.1016/j.exger.2017.12.005.

Sparkman, N.L., Buchanan, J.B., Heyen, J.R.R., Chen, J., Beverly, J.L., Johnson, R.W., 2006. Interleukin-6 facilitates lipopolysaccharide-induced disruption in working memory and expression of other proinflammatory cytokines in hippocampal neuronal cell layers. J. Neurosci. 26 (42), 10709-10716. https://doi.org/10.1523/ JNEUROSCI.3376-06.2006.

Stewart, J.C., Rand, K.L., Muldoon, M.F., Kamarck, T.W., 2009. A prospective evaluation of the directionality of the depression-inflammation relationship. Brain Behav. Immun. 23 (7), 936-944. https://doi.org/10.1016/j.bbi.2009.04.011.

Stuart, M.J., Baune, B.T., 2012. Depression and type 2 diabetes: inflammatory mechanisms of a psychoneuroendocrine co-morbidity. Neurosci. Biobehav. Rev. 36 (1), 658-676. https://doi.org/10.1016/j.neubiorev.2011.10.001.

Tracy, R.P., 2003. Emerging relationships of inflammation, cardiovascular disease and chronic diseases of aging. Int. J. Obes. 27 (3), S29-S34. https://doi.org/10.1038/ sj.ijo.0802497.

Treadway, M.T., 2016. The neurobiology of motivational deficits in depression-an update on candidate pathomechanisms. Curr. Top. Behav. Neurosci. 27, 337-355. https://doi.org/10.1007/7854_2015_400.

Treadway, M.T., Cooper, J.A., Miller, A.H., 2019. Can't or won't? Immunometabolic constraints on dopaminergic drive. Trends Cognit. Sci. 23 (5), 435-448. https:// doi.org/10.1016/j.tics.2019.03.003.

Tuck, M.K., Chan, D.W., Chia, D., Godwin, A.K., Grizzle, W.E., Krueger, K.E., Rom, W., Sanda, M., Sorbara, L., Stass, S., Wang, W., Brenner, D.E., 2009. Standard operating procedures for serum and plasma collection: early detection research network consensus statement standard operating procedure integration working group. J. Proteome Res. 8 (1), 113-117. https://doi.org/10.1021/pr800545q.

Valkanova, V., Ebmeier, K.P., Allan, C.L., 2013. CRP, IL-6 and depression: a systematic review and meta-analysis of longitudinal studies. J. Affect. Disord. 150 (3), 736-744. https://doi.org/10.1016/j.jad.2013.06.004.

van den Biggelaar, A.H.J., Gussekloo, J., de Craen, A.J.M., Frölich, M., Stek, M.L., van der Mast, R.C., Westendorp, R.G.J., 2007. Inflammation and interleukin-1 signaling network contribute to depressive symptoms but not cognitive decline in old age. Exp. Gerontol. 42 (7), 693-701. https://doi.org/10.1016/j.exger.2007.01.011.

Van der Kooy, K., van Hout, H., Marwijk, H., Marten, H., Stehouwer, C., Beekman, A., 2007. Depression and the risk for cardiovascular diseases: systematic review and meta analysis. Int. J. Geriatr. Psychiatr. 22 (7), 613-626. https://doi.org/10.1002/ gps.1723.

Wium-Andersen, M.K., Ørsted, D.D., Nielsen, S.F., Nordestgaard, B.G., 2013. Elevated Creactive protein levels, psychological distress, and depression in 73131 individuals. JAMA Psychiatr. 70 (2), 176-184. https://doi.org/10.1001/ 2013.jamapsychiatry.102.

Zalli, A., Jovanova, O., Hoogendijk, W.J.G., Tiemeier, H., Carvalho, L.A., 2016. Low-grade inflammation predicts persistence of depressive symptoms. Psychopharmacology 233 (9), 1669-1678. https://doi.org/10.1007/s00213-015-3919-9. 